\title{
Emotion analysis of teaching evaluation system based on Al techno-logy towards Chinese texts
}

\author{
Dandan Hong ${ }^{1}$, Zhan $\mathrm{Gao}^{1}$, Junfeng Luo ${ }^{1, *}$, Jun $\mathrm{Liu}^{1}$, Mo Xu${ }^{1}$, Zhihai Suo ${ }^{1}$, \\ and Xiangting $\mathrm{Ji}^{2}$ \\ ${ }^{1}$ Network and Information Center of Xi' an Jiaotong University,710049 Xi'an, Shannxi, P.R.China \\ ${ }^{2}$ Baidu Inc. Baidu Campus, 100085 Beijing, P.R.China
}

\begin{abstract}
In order to improve the teaching quality of graduate students, a quick method was designed to analyze the teaching evaluation comments in Chinese from students in the teaching evaluation system based on Baidu AI technology .So that it can help the teaching management department analyze the emotional inclination of students towards each course and grasp the trend and distribution of teaching quality accurately.The result of this article has shown that this method can analyze the students' evaluation text correctly and provide decision-making reference for teaching management departments or teachers themselves.
\end{abstract}

\section{Introduction}

Teaching evaluation is a process of judging the actual or potential value of teaching activities, which can provide decision-making services for teaching management. Up to now, more and more colleges and universities have begun to pay more attention to the evaluation work of teaching quality[1], and developed many teaching evaluation systems. If some evaluation systems were designed based on multiple specific indicators, it was easier to evaluate the teaching achievements of each course. But if there were lots of subjective comments or suggestions from students in the evaluation system, it would bring challenges to the accurate analysis of teaching results[2].

In recent years, lots of researchers has attracted attention to natural language understanding based on artificial intelligence technology. For example, Tong proposed a textual semantic analysis framework with active learning of the semantic structure knowledge in order to help computer systems to understand the texts in unstructured Chinese language[3]. Jia proposed a method to calculate the emotion intensity and realize the emotion classification based on emotion dictionary and semantic rules[4], which can help computer systems understand the natural language of human. Wu did research about sentence emotion classification for intelligent robotics based on word lexicon and emoticon emotions, which also aimed to analyse human language[5] .

Therefore, in order to improve the accuracy of teaching evaluation comments in Chinese text from students, this article proposed a fast and simple implementation method to realize

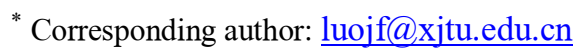


the emotion orientation analysis of Chinese text. The overall design of this method, the data structure and the key implementation steps will be explained in the following sections.

\section{Overall design of the method}

According to Figure1, there are five models in the method(basic data model,data integration model,data clearing model,data analysis model,data feedback model) that worked together to integrate with the teaching evaluation system of the university. So that it can help the teaching management department know the overall teaching quality of the university and help teachers understand the students' love degree of their own courses.

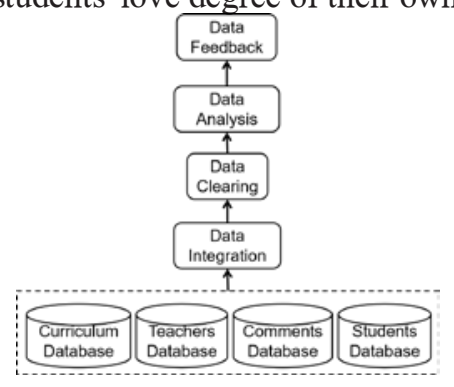

Fig. 1. Method structure.

As shown in Fig.1, the basic level(basic data model) is composed of four types of data(teachers' basic data, students' basic data, curriculum basic data and comments data). All data were associated by primary key and foreign key, which can help ETL tools to integrate data for upper level processing.

As shown in Fig.2, the IDs exiting in each table are primary keys. The TeacherID, StudentID and CurriculumID are foreign keys. They are connected with each other to the following calculation and subsequent analysis.

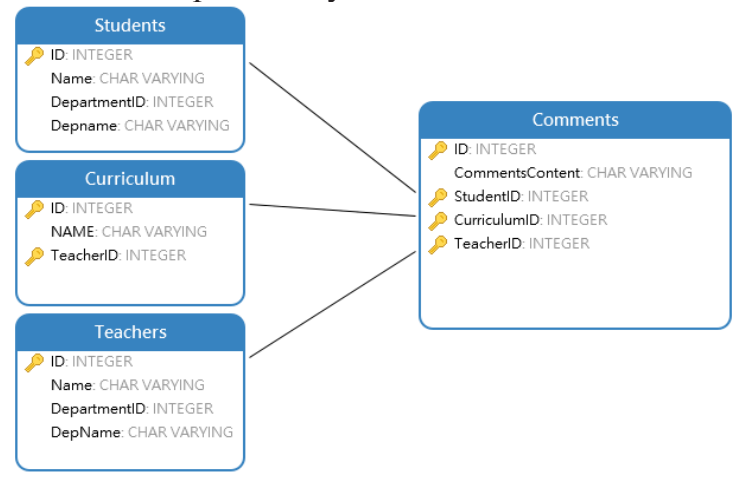

Fig. 2. Data structure of the basic information.

The other four modules work as bellow:

- Data integration module is responsible for extracting relevant data from the basic databases for subsequent heterogeneous data cleaning.

- Data clearing module is responsible for data re-examining and verifying, which aims to remove duplicate information, delete non-Chinese text reducing interference, and provide data consistency. For example, delete junk words or symbols, only reserve Chinese comments. Then reform these data into unified format in order to help the data analysis model to work efficiently. 
- Data analysis module is the core model of this article where AI text analysis is implemented. This part will be explained in detail in the next section.

- Data feedback model is responsible for showing the results of data analysis based on statistical charts and graphs.

\section{Implementation of Data analysis}

\subsection{Data sources and experimental procedures}

The data used in this article comes from teaching evaluation system of Xi'an Jiaotong University. 13 comments records towards teacher Li were selected. The experimental procedures is explained bellow.

- Step1. Apply a developer account from Baidu AI open platform and create a natural language processing application. Then record three important parameters which are APP_ID,APP_KEY,SECRET_KEY.

- Step2. Download four java SDK packages which are aip-java-sdk-version.zip,json20160810.jar,slf4j-api-1.7.25.jar and slf4j-simple-1.7.25.jar from Baidu AI platform.Then add them to a java project[6].

- Step3. Prepare data source and calculate the text data.

- Step4. Analyze the output result and visualize the data.

After the above steps, a complete emotional analysis process towards Chinese text was build effectively. The key java program is shown below in code section1. The analysis result will be explained in section3.2.

Code Section1. The key code example of AI emotion analysis

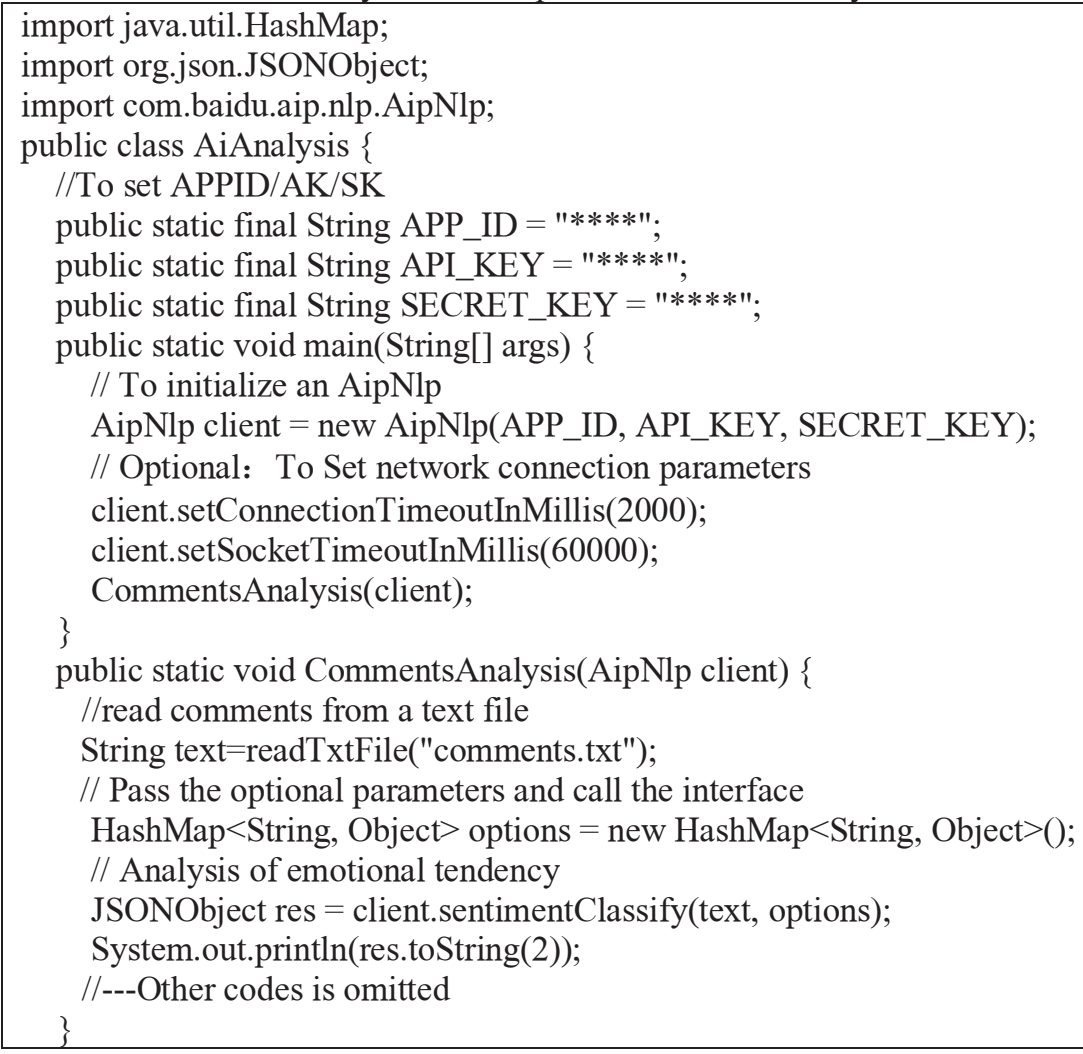


Table 1. Statistics of emotion analysis of Chinese texts (Translated in English for this paper).

\begin{tabular}{|c|c|c|c|c|}
\hline Comments after data clearing & positive_prob & sentiment & confidence & negative_prob \\
\hline $\begin{array}{l}\text { The content of the lecture is detailed but } \\
\text { difficult. }\end{array}$ & 0.0508446 & 0 & 0.887012 & 0.949155 \\
\hline Sometimes the Internet is stuck. & $5.56 \mathrm{E}-04$ & 0 & 0.998766 & 0.999444 \\
\hline $\begin{array}{l}\text { It is suggested to introduce some } \\
\text { modeling methods and skills of } \\
\text { intelligent algorithm software (Matlab, } \\
\text { mathemtica, lingo). }\end{array}$ & 0.526562 & 1 & 0.468759 & 0.473438 \\
\hline $\begin{array}{l}\text { Well, I hope it's meaningless to } \\
\text { remember so many formulas in the open } \\
\text { book examination. }\end{array}$ & 0.990616 & 2 & 0.979147 & 0.00938401 \\
\hline $\begin{array}{l}\text { Good. However, it is suggested that the } \\
\text { handouts should be distributed in } \\
\text { advance for preview. }\end{array}$ & 0.998375 & 2 & 0.996389 & 0.00162475 \\
\hline $\begin{array}{l}\text { The explanation is detailed and clear } \\
\text { with feedback }\end{array}$ & 0.910909 & 2 & 0.802019 & 0.0890913 \\
\hline $\begin{array}{l}\text { The lecture is very clear, let me have a } \\
\text { deeper understanding of the knowledge I } \\
\text { have learned before, thank you! }\end{array}$ & 0.999992 & 2 & 0.999983 & 7.60E-06 \\
\hline Try to use offline teaching method. & 0.696101 & 2 & 0.324669 & 0.303899 \\
\hline Experienced and knowledgeable. & 0.999731 & 2 & 0.999401 & $2.69 \mathrm{E}-04$ \\
\hline $\begin{array}{l}\text { Too much assessment content, learning } \\
\text { pressure. }\end{array}$ & 0.995093 & 2 & 0.989095 & 0.00490718 \\
\hline It can be explained more broadly. & 0.962033 & 2 & 0.91563 & 0.0379667 \\
\hline $\begin{array}{l}\text { It can increase the evaluation and } \\
\text { explanation of homework after class }\end{array}$ & 0.983262 & 2 & 0.962804 & 0.0167383 \\
\hline $\begin{array}{l}\text { The form of course assessment can be } \\
\text { simplified. The two teachers' different } \\
\text { homework requirements are piled } \\
\text { together and the burden is a little heavy. }\end{array}$ & 0.765215 & 2 & 0.478256 & 0.234785 \\
\hline $\begin{array}{l}\text { The teacher's explanation is very serious } \\
\text { and vivid. }\end{array}$ & 0.99983 & 2 & 0.999621 & $1.70 \mathrm{E}-04$ \\
\hline $\begin{array}{l}\text { The teacher has unique views on this } \\
\text { course, and the explanation is very } \\
\text { careful. }\end{array}$ & 0.999884 & 2 & 0.999742 & $1.16 \mathrm{E}-04$ \\
\hline $\begin{array}{l}\text { The introduction of the theory is from } \\
\text { simple to deep, step by step; the } \\
\text { explanation of the content is from point } \\
\text { to surface, meticulous. }\end{array}$ & 0.994184 & 2 & 0.987076 & 0.00581586 \\
\hline $\begin{array}{l}\text { It's hard and challenging to teach without } \\
\text { textbooks }\end{array}$ & 0.743518 & 2 & 0.430039 & 0.256482 \\
\hline
\end{tabular}

\subsection{Result Analysis}

After calculating the selected comments from students, the analysis result is shown in Table1. There are four result parameters to explain.

- The positive_prob means the probability of the positive category.

- The negative_prob means the probability of the negative category.

- The sentiment means the classification results of emotional polarity. 0 is for negative,

1 is for neutral, and 2 is for positive. 
- The confidence parameter means how much we can believe the result. If the the value of confidence parameter is smaller than $50 \%$, the result will be ignored because of unworthy to believe. So that there are four records (marked in italics in Table1) need to be deleted to avoid interference with the analysis results.

The visualization graph of the analysis upon Table 1 is shown in Figure3. It tells us that there are $84.62 \%$ students who have positive emotion towards teacher Li's course, $15.38 \%$ students who have negative emotion towards his course.

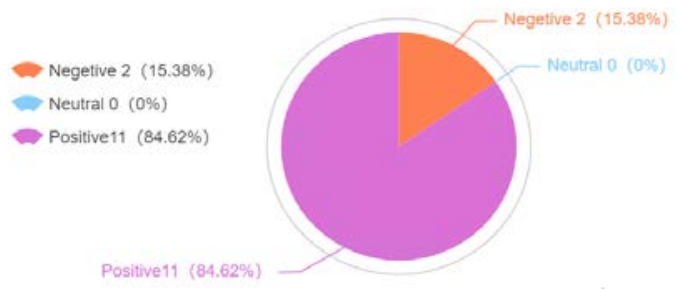

Fig. 3. Data visualization of the result.

\section{Conclusion}

Based on the above experiment, it was proved that using Baidu AI technology to analyze Chinese comments in teaching evaluation system can provide decision-making references for teaching management.

From the teachers' perspective, they can diagnose the effect of course teaching, so that they can help optimize their teaching methods and styles, and improve their teaching quality.

From the teaching management departments perspective, they can find out the most favorite courses of the students, and help themselves optimize the whole curriculum structure of the university in order to improve the overall teaching quality of the University.

In the future,we will pay more attention to emotion analysis in English language in order to help teaching management department know which course are popular in foreign students.

\section{References}

1. X. Hu,Y. Yang,X. Wu,Y. Li.Text analysis of teaching evaluation based on machine learning WCSE 2020: 2020 10th International Workshop on Computer Science and Engineering, p 19-24, 2020.

2. L. Yu,Y. Zhao.Sentiment analysis of Chinese short text based on teaching evaluation.Modern Electronics Technique.Vol. 42,No. 6,Mar.2019 .

3. J. Tong,Z. Wu,L. Qi,L.Du,L. Xu,J. Yu. Application of natural language understanding in Chinese power dispatching centre . E3S Web of Conferences 182, 02002 (2020)

4. K. Jia,Z. Li .Chinese micro-blog sentiment classification based on emotion dictionary and semantic rules.2020 International Conference on Computer Information and Big Data Applications, CIBDA 2020, p 309-312, April 2020.

5. Y. Wu,X. Kang,K. Matsumoto,M. Yoshida,K. Xielifuguli,K. Kita.Sentence Emotion Classification for Intelligent Robotics Based on Word Lexicon and Emoticon Emotions.2018 IEEE International Conference of Intelligent Robotic and Control Engineering, IRCE 2018, p 140-143, October 15, 2018.

6. NLP-JAVA-SDK.https://ai.baidu.com/ai-doc/NLP/Nk6z52ci5 